\title{
Assessment of the sorption potential of the plant I. Sativum I. in the process of formation of the biogeochemical barrier
}

\author{
Sergei Kornilkov ${ }^{1 *}$, Natalia Antoninova ${ }^{1}$ and Artem Sobenin ${ }^{1}$ \\ ${ }^{1}$ Federal State Institution of Science, Institute of Mining of the Ural Branch of the Russian Academy \\ of Sciences, 620075, Yekaterinburg, Russia
}

\begin{abstract}
For many years of industrial development of the Ural region, the mining industry remains one of the main components of the economy, the development of which is accompanied by large-scale environmental pollution and the accumulation of a significant amount of man-made waste with a high potential for negative impact. The article presents the results of experimental studies on the accumulation of heavy metals by L. sativum L. plants, in order to develop the principles of the formation of artificial biogeochemical barriers. As part of the research on the territory of the enterprise leading the development of the copper pyrite deposit, samples of dump waters were taken, which, in turn, were subjected to chemical analysis and a test to assess their phytotoxic (in the absence of a substrate) potential for seed germination and root growth in a model of L. sativum L. The samples were diluted in distilled water to obtain 8 different concentrations $(1: 80,1: 60,1: 40,1: 20,1: 10,1: 5,1: 2,1: 1)$, and the effect of waste water without dilution with water, and distilled water was used as a control. In addition, the total amount of metals $(\mathrm{Cr}, \mathrm{Cu}, \mathrm{Ni}, \mathrm{Pb}, \mathrm{Co}$ and $\mathrm{Zn})$ was determined. The data obtained demonstrated the phytotoxicity of the dump waters, a decrease in root growth in solutions with concentrations of 1: 1, 1: 2, 1: 5, 1:10 and 1:20 was noted, it was shown that these biological objects have accumulating properties with respect to a number of heavy metals.
\end{abstract}

Keywords: dump waste water, heavy metals, accumulation, biogeochemical barriers, land resources

\section{Introduction}

The progressive degradation of the natural environment of the Urals remains a serious problem at the present time, despite the fact that at the present stage of development of the mineral resource complex, the environmental factor is gradually becoming one of the main constraints in the selection and assessment of technical and technological solutions $[1,2]$. The result of intensive industrial development with a negative aspect is the pollution of land resources with heavy metals, therefore the need for monitoring, control and cleaning from

\footnotetext{
${ }^{*}$ Corresponding author: natal78@list.ru
} 
pollution with heavy metals, such as copper $(\mathrm{Cu})$, zinc $(\mathrm{Zn})$, nickel $(\mathrm{Ni})$, lead $(\mathrm{Pb})$, chromium $(\mathrm{Cr})$, cobalt $(\mathrm{Co})$ has become especially important in recent years [3].

The idea of using phytoextraction to remove heavy metals and their compounds was first proposed in 1983, but the concept was actually implemented at the beginning of the 21 st century in relation to technogenically polluted groundwater and other water flows (RL Chaney, M. Malik et al, 1997; RL Chaney et al, 1997; RJ Henry, 2000; C. Garbisu and I. Alkorta, 2001) The buffer properties of soils have also been studied in sufficient detail (T.A. Sokolova, M.S. Alinina (1991), M.I. Gerasimova , M.N. Strogonova (2003)), however, the issues of creating natural or artificial geochemical barriers on the way of technogenic flows require additional study, because internal factors, mainly the form of finding a chemical element in the crystal lattice of minerals, its pliability to weathering, and external, such as temperature, alkaline-acid and redox factors. The intensity of migration often sharply decreases at a short distance, which leads to a significant concentration of elements - the formation of barrier functions at the boundaries of rocks of various compositions, at the boundary of soil horizons. But in natural ecosystems, during the formation of barriers, an important factor is also the biological component, which determines the need to study the conditions for the formation of biogeochemical barriers for the purposes of environmental rehabilitation. In connection with the above, the issues of studying the processes that determine the accumulation and migration of heavy metals in technogenically contaminated ecosystems in the regions where enterprises of the mining and metallurgical complex operate, the use of biotechnological methods of soil detoxification using battery plants is a very urgent problem, the solution of which makes it possible to establish relationships between the mobility of chemical elements in technogenic soils and technogenically contaminated soils, as well as their accumulation by plants-accumulators, providing a biologically specified level of impact, which in turn can become the basis for the formation of artificial biogeochemical barriers in order to develop methods of ecological rehabilitation of disturbed ecosystems.

This work was aimed at assessing the phytotoxic potential of dump waters formed during the development of copper pyrite deposits in relation to seed germination and their growth in the model of the cress plant (Lepidium sativum L.) with further use of the accumulative properties of the biological component in the development of principles for the formation of biogeochemical barriers.

\section{Materials and methods}

Bottom water samples were taken during the summer field research on the territory of the copper pyrite plant. The main useful components of the deposit are copper, zinc, sulfur. The main copper-bearing minerals are chalcopyrite and covellite. Besides them, copper is bound in chalcocite, fahlores and copper sulfates (chalcanthite, brochantite). Zinc is represented by sphalerite and to a small extent zinc sulfate (calamine). The main volume of sulfur is associated with the main ore mineral - pyrite, as well as marcasite, chalcanthite, sphalerite. In all types of ores, associated components were identified that are characteristic of pyrite deposits: gold, silver, selenium, tellurium, cadmium, indium, gallium, germanium, thallium, bismuth, lead, barium. Arsenic and lead compose their own minerals (tenantite, galena). Minerals of these elements are in close intergrowth with the main ore-forming minerals pyrite, chalcopyrite and sphalerite. The samples were stored in plastic disposable flasks with refrigeration until physicochemical and biological analyzes.

The measured parameters were $\mathrm{pH}$, and elemental analysis. An AA-240 FS atomic absorption spectrometer (Varian Optical Spectr. Instrum, Australia) with a deuterium lamp as a background corrector was used to determine the total content of $\mathrm{Cu}, \mathrm{Zn}, \mathrm{Pb}, \mathrm{Co}, \mathrm{Cr}$, and Ni. Samples were mineralized in concentrated $\mathrm{HNO}_{3}$ using a MARS 5 laboratory 
microwave system (CEM, USA). The $\mathrm{pH}$ was determined using a HI $99121 \mathrm{~N}$ pH meter (Hanna, Germany).

To study the phytotoxicity, the bottom wastewater was diluted in distilled water to obtain 8 different concentrations: 1:80 to $1: 1$, the effects of wastewater without dilution with water were also evaluated, and distilled water was used as a control.

\section{Experimental technique}

$5 \mathrm{ml}$ of previously prepared dilutions of waste water and a control solution were poured into each Petri dish, then filter paper was placed in it, and 50 pieces of watercress were placed directly on the paper. Each dilution was made in 3 replicates. There were 26 Petri dishes in total. The experiment was carried out for 72 hours after which the plants were fixed in a $70 \%$ ethanol solution.

\subsection{Seed germination and root growth}

The number of germinated seeds was determined at time points 12, 24, 36, 48 and 72 hours. After 72 hours, the length of all plants was measured.

Based on these data, the percentage of relative germination (RGP) corresponding to the percentage of germinated seeds with each treatment, relative root growth (RRG) and germination rate index (GI) were obtained [4]. Seeds were considered germinated if the length was at least $2 \mathrm{~mm}$.

$$
\text { Gs } / \mathrm{Gc} * 100=\mathrm{RGP}, \%
$$

where Gs is the number of germinated seeds in the sample, and Gc is the number of germinated seeds in the control (distilled water).

$$
\mathrm{Ls} / \mathrm{Lc} * 100=\mathrm{RRG}, \%
$$

where Ls is the length of the root of germinated seeds in the sample, and Lc is the length of the radicular of the germinated seed in the control (distilled water).

$$
(\mathrm{RGP} * \mathrm{RRG}) / 100=\mathrm{GI}
$$

\subsection{Results and discussion}

\subsubsection{Chemical analysis of dump waters, seed germination and root development}

The results of the chemical analysis of the waste waters revealed an acidic $\mathrm{pH}-2.5$ and a composition with a large amount of dissolved solids (Table 1).

Table 1. Chemical analysis of waste water and $\mathrm{pH}$

\begin{tabular}{|c|c|c|c|c|c|c|}
\hline Elemental & $\mathrm{Cu}$ & $\mathrm{Zn}$ & $\mathrm{Ni}$ & $\mathrm{Cr}$ & $\mathrm{Co}$ & $\mathrm{Pb}$ \\
\hline Concentration, mg\l & 23 & 38.5 & 0.6 & 0.03 & 0.52 & 0.22 \\
\hline
\end{tabular}

It is known that acidic dump wastewater inhibits the development of biological plant resources, causing soil salinization. Increased concentrations of metal salts in the soil cause osmotic stress in plants and, therefore, prevent the absorption of nutrients and water, as a result, metabolism is impaired and, as a rule, the productivity of the plant decreases [5].

Experimental studies have shown that, in L. sativum seeds that were exposed to the dump water formed during the mining of a copper pyrite deposit, poor germination and development of the root system was observed due to the deterioration of conditions for the absorption of water and other elements necessary for life by the plant. 
Consequently, the effect of increased concentrations of heavy metals (solutions 1: 1, 1: $2,1: 5,1: 10$ and 1:20) slows down seed germination, which is confirmed by both a decrease in the germination rate index (GI) (Table 2), as well as and the indicator of the relative growth of roots (Fig. 1).

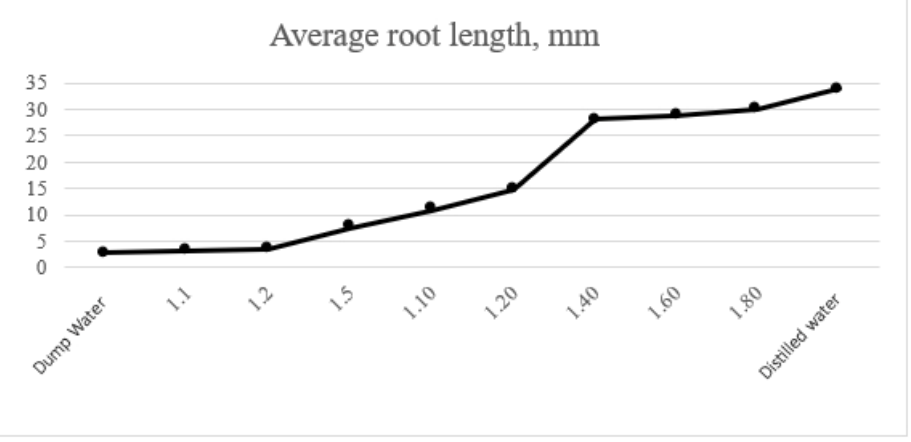

Fig. 1. Root growth in L. sativum L. seedlings treated with different concentrations of dump waters for 72 hours.

The relative percentage of germination $(\mathrm{RGP} \%)$ and the relative growth of the root (RRG, \%) were used to determine the germination index (GI, \%). The germination index takes into account not only germinated seeds, but also root growth. And the parameters RGP and RRG are used to compare the sample with the control in distilled water.

No clear and formal criteria could be found, but, according to Agerre and Gavazzo 2012 [6], GI values of $80 \%$ or more indicate the absence of phytotoxic substances, or they are found at very low concentrations. GI values of $50 \%$ indicate that the presence of phototoxic substances is strong and that values from 50 to $80 \%$ may indicate the presence of these substances. Therefore, it can be argued that a GI value below $50 \%$ implies phytotoxicity of the test objects.

In connection with the above, the results of experimental studies to assess the effect of increased concentrations of a number of heavy metals have shown a tendency to increase the phytotoxicity of sediment from dump waters with an increase in the concentration of solutions (Table 2).

Table 2. Average plant length (mm), relative percentage of germination, relative growth and seed germination index of L. sativum L.

\begin{tabular}{|l|c|c|c|c|}
\hline Code / indicator & Root length (mm) & RGP (\%) & RRG (\%) & GI (\%) \\
\hline Distilled water & 33.92 & 100 & 100 & 100 \\
\hline Dump water & 2.76 & 86 & 8.14 & 7.00 \\
\hline $1: 1$ & $3.17 \pm 0.09$ & $94 \pm 5.3$ & $9.3 \pm 0.28$ & $8.7 \pm 0.7$ \\
\hline $1: 2$ & $3.49 \pm 0.44$ & $96 \pm 2$ & $10.28 \pm 1.29$ & $9.8 \pm 0.6$ \\
\hline $1: 5$ & $7.53 \pm 0.95$ & $98 \pm 0$ & $22.19 \pm 2.79$ & $21.7 \pm 0.1$ \\
\hline $1: 10$ & $10.93 \pm 1.4$ & $94.6 \pm 4.2$ & $32.2 \pm 4.13$ & $30.5 \pm 1.1$ \\
\hline $1: 20$ & $14.69 \pm 2.02$ & $96.6 \pm 1.2$ & $43.3 \pm 5.96$ & $41.8 \pm 0.3$ \\
\hline $1: 40$ & $28.1 \pm 1.37$ & $98.6 \pm 2.3$ & $82.8 \pm 4$ & $81.7 \pm 0.4$ \\
\hline $1: 60$ & $28.6 \pm 0.38$ & $96 \pm 3.5$ & $84.5 \pm 1.11$ & $81.1 \pm 1.3$ \\
\hline $1: 80$ & $29.87 \pm 0.51$ & $95.3 \pm 3.1$ & $88.0 \pm 1.51$ & $83.9 \pm 0.5$ \\
\hline
\end{tabular}


Thus, concentrations from 1: 1 to 1:20 can be considered phytotoxic (GI less than 50\%). Concentrations 1:40 - 1:80 are non-toxic and close in value to distilled water $(\mathrm{GI}=81.1$ $83.9 \%)$.

It was shown that in each analyzed sample the relative percentage of seed germination was similar to the control in distilled water. In all likelihood, this may be due to the presence of components in solutions that promote the rapid growth and development of seedlings. The following concentrations of solutions made it possible to achieve close values of the relative percentage of seed germination in comparison with the control: 1: 40$82.8 \% ; 1: 60-84.5 \% ; 1: 80-88 \%$, and the length of plant roots at the same concentrations was $28.1 \mathrm{~mm}, 28.6 \mathrm{~mm}$, and $29.87 \mathrm{~mm}$, respectively (Table 2).

\subsubsection{The content of heavy metals in L. sativum seedlings}

It is known that the total soil contamination characterizes the gross HM content, and the availability of elements for plants is determined by their mobile forms. Therefore, mobile compounds of chemical elements represent the most important group of compounds from the point of view of plant nutrition. They are extracted from the soil with various solvents, the action of which is comparable to the action of natural waters and plants - these are dilute solutions of salts, acids and bases.

Copper $(\mathrm{Cu})$, zinc $(\mathrm{Zn})$, nickel $(\mathrm{Ni})$, lead $(\mathrm{Pb})$, chromium $(\mathrm{Cr})$ and cobalt were selected among heavy metal pollutants identified as hazardous to human health and plant development in experimental studies Co. These toxic elements easily spread into the environment due to adsorption by soil, including river sediments, plants and fish [7]. An excess amount of these elements in soils can lead to a decrease in its biological activity, which in turn can affect the development of plants [8]. The results of the chemical analysis of L. sativum L. seedlings are shown in Table 3.

Table 3. Metal content in L. sativum L. seedlings treated with various concentrations of dump waters for 72 hours.

\begin{tabular}{|c|l|c|c|c|c|c|c|}
\hline \multirow{2}{*}{ № } & \multirow{2}{*}{ Code } & \multicolumn{7}{|c|}{$\mathrm{Mg} / \mathrm{kg}$} \\
\cline { 3 - 8 } & & $\mathrm{Cu}$ & $\mathrm{Zn}$ & $\mathrm{Ni}$ & $\mathrm{Cr}$ & $\mathrm{Co}$ & $\mathrm{Pb}$ \\
\hline 1 & Dump water & 1036.6 & 1571.4 & 4.3 & 0.0 & 0.0 & 1.3 \\
\hline 2 & $1: 1$ & 1618.8 & 2441.6 & 4.2 & 0.0 & 0.0 & 0.6 \\
\hline 3 & $1: 2$ & 1532.4 & 1466.2 & 1.9 & 0.0 & 0.0 & 0.6 \\
\hline 4 & $1: 5$ & 633.7 & 1104.3 & 4.7 & 0.0 & 0.0 & 0.7 \\
\hline 5 & $1: 10$ & 307.2 & 751.0 & 3.5 & 0.0 & 0.0 & 0.6 \\
\hline 6 & $1: 20$ & 153.0 & 615.3 & 1.4 & 0.0 & 0.0 & 0.6 \\
\hline 7 & $1: 40$ & 80.2 & 351.0 & 3.2 & 0.0 & 0.0 & 0.4 \\
\hline 8 & $1: 60$ & 44.4 & 207.8 & 2.8 & 0.0 & 0.0 & 0.3 \\
\hline 9 & $1: 80$ & 88.3 & 53.6 & 1.1 & 0.0 & 0.0 & 0.0 \\
\hline 10 & Distilled water & 0.3 & 1.9 & 0.0 & 0.0 & 0.0 & 0.0 \\
\hline
\end{tabular}

Elemental analysis showed a high content of metals $\mathrm{Cu}, \mathrm{Zn}, \mathrm{Ni}, \mathrm{Pb}$ in $\mathrm{L}$. sativum seedlings L. Cr and Co were not found in the studied samples. 
Thus, the results of experimental studies showed a tendency to an increase in the content of inorganic substances in the plant under study, depending on the increase in the concentration of solutions (Fig. 2).

In plants treated with solutions with concentrations: 1:40; 1:60 and 1:80 lead was found in values not exceeding the MPC, in all other solutions, an excess of MPC was recorded for $\mathrm{Cu}$ from 17.6 to 207 times, for $\mathrm{Zn}$ from 5.3 to 241 times, for Ni from 2.2 to 9.4 and in $\mathrm{Pb}$ from 1.2 to 2.6 times. In the control Petri dish, where the plants were grown in distilled water, no excess of MPC was detected for any of the metals.
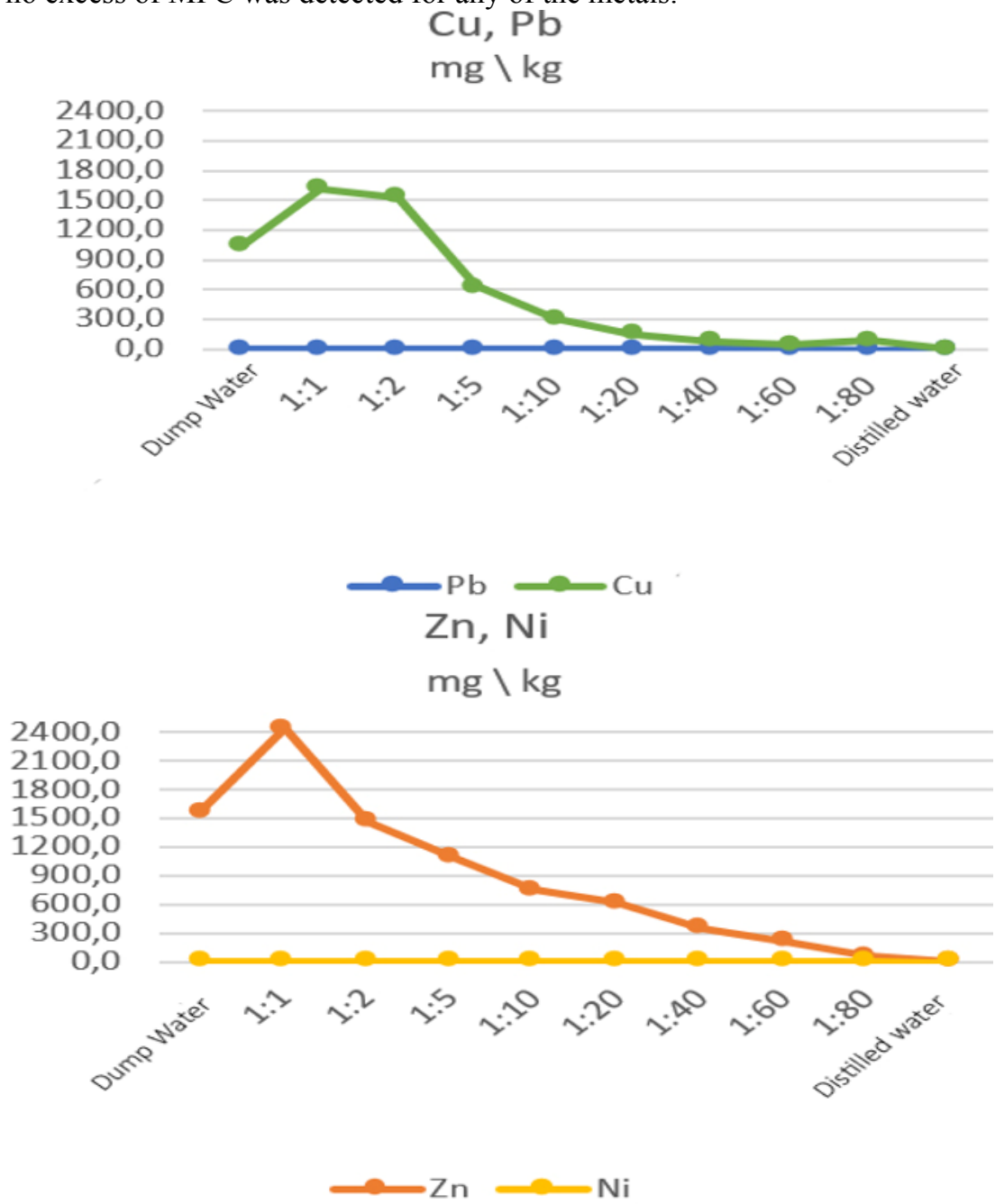

Fig. 2. Contents of $\mathrm{Zn}, \mathrm{Cu}, \mathrm{Ni}, \mathrm{Pb}$, in $\mathrm{L}$. sativum $\mathrm{L}$. seedlings treated with different concentrations of dump waters for 72 hours.

Based on the data obtained, it can be concluded that L. sativum L. plants adsorb all these elements well and the actions of these heavy metals caused stress in plants and negatively affected the growth and development of seedlings, which led to low values of RRG, GI indicators in solutions with concentrations: $1: 20 ; 1: 10 ; 1: 5 ; 1: 2 ; 1: 1$. 


\section{Conclusions}

In this article, the results of experimental studies on the accumulation of heavy metals by L. sativum L. plants were obtained and analyzed in order to develop the principles of the formation of artificial biogeochemical barriers. The presented data demonstrated the phytotoxicity of the dump waters; in addition, a decrease in root growth in solutions with concentrations of 1: 1, 1:2,1:5,1:10 and 1:20 was noted, as well as that these biological objects accumulate heavy elements in In some cases, the excess of the MPC was recorded up to 200 or more times.

Using the example of an agricultural crop with the ability to accumulate high concentrations of the studied elements, the prospects for using these plants as biological indicators are shown, since as the concentration of heavy metals in solution decreases, the concentration of this element in plants also decreases.

Thus, the data obtained are the basis for the development of methods for the ecological rehabilitation of disturbed ecosystems, in terms of assessing the possibility of carrying out phytoexraction measures during the formation of artificial biogeochemical barriers with the formation of a chain of a biological component that is sensitive to each chemical element.

The article was prepared within the framework of the RFBR grant No. 20-45-660014 "Investigation of the regularities of migration and accumulation of heavy metals in natural systems experiencing a local technogenic load of enterprises of the mining and metallurgical complex in order to develop effective methods of their ecological rehabilitation" and state task "Development of methods for geoinformation monitoring of mining and geological objects with the assessment of the state of mining enterprises as natural and technological systems»»

\section{Literature}

1. N. Antoninova L. Shubina, Gorny Zhurnal, 8, 64-68 (2013)

2. L. Rybnikova, P. Rybnikov, GIAB, 3, 488-500 (2020)

3. S. Kornilkov, GIAB, S37, 177-186 (2019)4. A. Fuentes, M. Llorens, J. Saez, M. Aguilar, J. Ortuno, V. Meseguer. J. Hazad. Mater, 3, 161-169 (2004)

5. A. Parida, A. Das, Ecotoxicology and Environmental Safety, 60, 324-349 (2005)

6. Y. Aguerre, G. Gavazzo. The 45th ABTCP international pulp and paper congress and VII Ibero American Congress on Pulp and Paper Research (2012)

7. P. Govind, S. Madhuri. Research Jour-nal of Animal Veterinary and Fishery Sciences, 2, 17-23 (2014)

8. K. Phoungthong, H. Zhang, L. Shao, P. He, Chemosphere, 146, 547-554 (2016) 